\title{
Proposta para o Aproveitamento Turístico de Áreas Arqueológicas da Bahia, Brasil
}

\section{Carlos Etchevarne}

RESUMO: Os sítios arqueológicos, correspondentes a vestígios de populações pré-históricas, podem ser incluídos em programas de desenvolvimento regional, especialmente aqueles que promovem o turismo. Quando bemexploradas, as localidades arqueológicas podem funcionar como pólos de atração de visitantes, como são os casos das localidades de Perigord (França) e São Raimundo Nonato (Brasil). Na Bahia, em função de programas governamentais de fomento ao turismo, propõem-se algumas diretrizes para a criação de Parques Arqueológicos, conjugando o turismo e a preservação do patrimônio arqueológico.

PALAVRAS-CHAVES: Turismo e arqucologia; sítios; arte rupestre; Perigord; São Raimundo Nonato; criação de parques arqueológicos; Bahia; Brasil.

ABSTRACT: Archaeological sites, specifically those boasting vestiges of prehistoric populations, should be included in regional development programs, especially those catering to tourism. When weel-exploited, these archaeological areas can serve as poles of attraction for vacationers, as has been the case in Perigord (France) and São Raimundo Nonato(Brazil). In Bahia, in response to governmental programs aimed at promoting tourism, we have proposed a number of directives for the creation of Archaeological Parks, thus forging an essential link between tourism and the preservation of the region's archaeological heritage.

KEY WORDS: Tourism and archaeological; sities; rupestral art; Perigord; Sâo Raimundo Nonato; creation of archaeological parks; Bahia; Brazil.

1. Professor de Arqueologia do Departamento de Antropologia da Universidade Federal da Bahia. Doutor pelo Institut de Paléontologie Humaine (Muséum d'Histoire Naturelle de Paris). Responsável pelo Setor de Arquelogia do Museu de Arqueologia e Etnologia da Universidade Federal da Bahia.

End. para corresp.: Museu de Arqueologia e Etnologia da Universidade Federal da Bahia (MAE/UFBA). Terreiro de Jesus, s/n. Antiga Faculdade de Medicina - 40025-010 - Salvador - BA - Brasil - Fone/Fax: (071) 321-3971. 


\section{Sítios Arqueológicos e Turismo}

Em diferentes partes do mundo, o potencial arqueológico de uma dada cidade ou região vem sendo objeto de atenção especial por parte de programas de desenvolvimento econômico. E, ao contrário do que se imagina, essa atenção não está limitada unicamente àqueles lugares onde existam conjuntos arquitetônicos monumentais, a exemplo dos espaços clássicos do mundo mediterrânico ou mcsmo aqueles referentes às sociedades andinas. Nos últimos anos, o interesse pelo trabalho e, mais especificamente, pelos achados arqueológicos vem se ampliando, abarcando todas as localidades onde a presença humana deixou vestígios menos espetaculares, mas igualmente valiosos, posto que atestam processos históricos desenvolvidos em um determinado lugar.

Casos de integração das localidades arqueológicas, incluídas as denominadas "pré-históricas", a programas de atividades econômicas têm sido realizados com sucesso, originando-se em torno do locus de trabalho (sítios arqueológicos) e das pesquisas a ele referentes, uma gama de ações de certo impacto no âmbito local ou regional, proporcionando um dinamismo particular. A pesquisa arqueológica, por si só, constitui o momento inicial desse dinamismo.

Em primeiro lugar, deve-se considerar o impacto produzido pela movimentação de pessoas e de bens de consumo durante os trabalhos de campo, o que significa, em muitos casos, a irrupção em um mundo social e econômico estável (quando não estagnado). Com efeito, durante o período das escavações, uma equipe de arqueólogos, auxiliares e outros especialistas (geólogos, biólogos, antropólogos, topógrafos, fotógrafos, etc.) transfere-se periódica ou permanentemente para 0 local, presumindo, no mínimo, a provisão de moradia e alimentação, assim como mão-de-obra braçal, guias e transporte não-automotor (cavalos, embarcações).

Em um segundo momento, uma vez terminadas as escavações, à criação de pequenos centros de pesq̧uisas ou de museus locais para receber o material arqueológico coletado e estudado corresponde a uma situação mais duradoura de entrada de recursos. Nesse sentido, visitas públicas ao museu, reuniões ou seminários de especialistas, venda de publicações e de reproduções de objetos significam, indubitavelmente, uma fonte de ingresso de certo peso. Enfim, existe uma movimentação substancial de visitantes, turistas ou especialistas, com necessidades específicas, que implica, por sua vez, a preparação adequada da população local, em terımos de aprendizado para gerenciamento dos recursos originados pelas pesquisas. A seguir, analisam-se algumas localidades arqueológicas situadas ná França e no Brasil.

\section{Região de Perigord (França)}

A área onde se situam algumas localidades arqueológicas na região de Perigord, no sudoeste da França, margeia o rio Vezère, afluente do Dordonha, e seus tributários Manaurie, Moustier e Grande Beune, desde Montiagnac atć Le Bugue.
A região apresenta, sobre uma topografia de profundo vales recortados, grand número de grutas e abrigos que têm sido hábitat de diferentes grupos humanos, em vários momentos de evolução histórica. É precisamente nessa região que foram localizados restos do Homo sapiens neandertalensis e dos mais antigos fHomo sapiens sapiens da França, e que também é apresentado um dos mais belos conjuntos de arte rupestre já encontrados na Europa. Existem, ainda, vestígios materiais deixados por representantes do Homo erectus, a espécie mais antiga do ê̂nero Homo, encontrada em território europeu (Delluc et al., 1990; Laboratoire de Préhistoire ... 1984)

O conjunto de sítios arqueológicos nos vales do Vezère e seus afluentes, na verdade, representa o apanhado de todos os períodos pré-históricos da Europa, compreendidos no Paleolítico Inferior, Médio e Superior, que, em alguns casos recebem os nomes de sítios ali localizados: La Madelaine, periodo Madaleniense; Le Moustier, Musteriense; La Micoque, Micoquense, por exemplo. Percorrendo-36 as localidades desses vales, tem-se a ocasião ímpar de ver representados, cronologicamente, os elementosculturaisdistintivos de cada estágio, articulados ao próprio ambiente onde foram desenvolvidos. A arte parietal ocupa, nessa região, um lugar dedestaque. Assim. pode-se observar a mplo mostruário das diversas manifestações gráficas, abarcando desde os motivos gravados e esculpidos em baixo relevo do Aurinhacense até as profusas pinturas animalísticas do Madaleniense.

Em posição de destaque absoluto encontra-se, sem dúvida alguma, a grita de Lascaux, um dos sítios mais setentrionais dessa área arqueológica. Devido às esplendorosas pinturas naturalistas policromas, lípicas do período Madaleniense, que recobrem grande parte das paredes e do teto da grupa, Lascaux é denominada a "Capela Sistina da Pré-História" e ponto de passagem obrigatório de arqueólogos e historiadores da arte (Vialou, 1989; Leroi-Gourhan, 1992).

Desde a abertura ao público, o fluxo de visitantes de Lascaux, especialistas ou não, foi tão intenso que provocou deterioração na pigmentação dos grafismos, especialmente pela introdução de bactérias e outros microorganismos. Por esse motivo, hoje sua visitação está rigorosamente controlada e restrita a especialistas devidamente autorizados e para o atendimento do público leigo interessado, fo realizada uma réplica de parte da gurta (Lascaux II), próxima à original, aberta à visitação durante todo o ano. Esses fatos permitem não somente perceber a quantidade de visitantes que um só sítio arqueológico mobiliza, como também a necessidade de cuidados especiais de preservação quando da articulação entre sítios arqueológicos e ação turísíica.

Ainda na região de Lascaux, a jusante do Vezère, seguem-se mais de 20 localidades arqueológicas, entre as quais se destacam Blanchard, Le Moustier, La Madelaine, La Miooque, Cro-Magnon, Pataud, LaugerieHautee Laugerie Basse, Gorge d'Enfer, Font de Gaume, Combarelle, CapBlanc, Laussel; um pouco mais afastados encontram-se as de La Ferrasie e Rouffignac. Todos os sítios podem ser visitados e apresentam muscus anexos ou oferecem musealização dos próprios sítios. No primeiro

bógico; no segundo, mostra-se didaticamente as sucessivas ocupações do espaço em setores com estratigrafias testemunhas. 
A população local, evidentemente, obtém beneficios do fluxo de visitantes, existindo uma organização de atividadeseconômicas voltadas para a recepção desse contingente de visitas. Além dos museus, com suas exposições permanentes existem ainda pequenos centros de pesquisas, como o do Abrigo Pataud, perto de Cro-Magnon, onde eventualmente se congregam profissionais e estudantes, em seminários e reuniões de trabalho. Os visitantes diletantes, por sua vez, têm a disposição excursões organizadas e guias para cada sítio, atendendo os interesses de cada visitante. Como conseqüência dessas atividades, foram fomentados dispositivos comerciais que facilitam a permanência dos visitantes na região: rede de pequenos hotéis, pousadas, campings, restaurantes, bares e lojas de aprovisionamento. Para divulgação dos resultados dos estudos, existem publicações (catálogos, folhetos, revistas e livros, com diferentes niveis de especialização), slides, fitas de vídeo, reproduções de objetos, cartões postais e pôsteres.

Exemplos como esses, no qual se perfila um conjunto de atividades econômicas ligadas a sítios arqueológicos e suas pesquisas, podem ser encontrados em muitas outras partes do mundo.

\section{São Raimundo Nonato (Brasil)}

No âmbito brasileiro, talvez o caso mais notório seja o da localidade de São Raimundo Nonato, na Serra da Capivara, sertão semi-árido do Piaui, onde vem sendo desenvolvidas pesquisas contínuas desde 1973. Os trabalhos levados a cabo pela equipe dirigida pela arqueóloga Niède Guidon, da École de Hautes Études, Paris, que inclui pesquisadores brasileiros e estrangeiros, têm provocado profundas alterações na área de São Raimundo Nonato, transformando-a em pequeno pólo de desenvolvimento econômico regional. Nessa região, os trabalhos sistemáticos de escavações vêm proporcionando resultados importantes, além de terem sido registrados na área cerca de 400 sítios (mais de 200 com arte rupestre). Encontrase no atual parque da Serra da Capivara o abrigo Toca do Boqueirão da Pedra Furada, cuja análise dos achados vem permitindo identificar os mais antigos vestígios da presença do homem na América (Guidon, 1984; 1992).

Por essa razão, em São Raimundo Nonato, além da presença dos grupos permanentes de profissionais, existe constante afluência de arqueólogos visitantes, de estagiários que participam das escavações, por períodos, e de público nãoespecialista, mas igualmente interessado pelos trabalhos arqueológicos. Também foi criado um museu local, sendo alguns sítios abertos à visitação, após receberem tratamento especial de maneira a permitir a circulação dos visitantes por entre escavações, sem prejudicar os testemunhos arqueológicos deixados propositadamente à vista.

A concretização do Museu do Homem Americano, ao mesmo tempo centro de pesquisa e local de exposições, no municipio de São Raimundo Nonato, tornou esse lugar um marco de referência arqueológica tanto no Brasil como no Exterior, chegando a se constituir ponto de convergência para as discussões sobre a antigüidade do homem na América. A esse respeito, o Museu congregou, em 1993, especialistas de todo o mundo em uma conferência dedicada ao tema (Anais da Conferência..., 1996).

Como conseqüência de todo o aparato criado para a consolidação e divulgacão das pesquisas na Serra da Capivara, têm-se produzido, na região, algumas modificações substanciais de ordem econômica, especialmente na produção e circulação de bens de consumo. Outras, não menos substanciais, são de caráter urbanistico, educacional (especialmente no que se refere ao patrimônio arqueológico e ambiental) e até de saúde pública, algumas não-intencionais e outras programadas, que chegaram, algumas vezes, a serem propostas às autoridades locais e levadas à prática pela própria equipe de pesquisa.

\section{Aproveitamento Turistico de Áreas Arqueológicas na Bahia (Brasil)}

Os dois exemplos mencionados, os sítios de Perigord, na França, e os de São Raimundo Nonato, no Piaui, apesar das diferenças de ambiente natural, culturas arqueológicas e cronologia, dão idéias do dinamismo socioeconômico que podem produzir os trabalhos de pesquisa em sítios arqueológicos nas localidades onde eles se encontram. Isso invalida a concepção comum sobre esses tipos de estudos, considerando-os como referentes a um passado remoto, sem vinculação com o presente, desconhecendo assim o potencial de ingerência no âmbito prático do cotidiano contemporâneo. Ao contrário, parece que, para algumas populações atuais, a busca e reconstituição arqueológica de um passado, mesmo que longínquo, servem de instrumento para abrir-lhes espaço dentro da sociedade industrializada do presente.

Por isso, apresenta-se, a seguir, a proposta de diretrizes básicas para o aproveitamento de áreas arqueológicas como focos turisticos, tomando-se como exemplo o Estado da Bahia, postoque, neste momento, existe interesse estadual de incentivo ao turismo, talvez mesmo o de maior investimento no âmbito brasileiro (Burman, 1995; Queiroz, 1995)

É possivel pensar no aproveitamento turístico-econômico dos sítios arqueológicos na Bahia? A principio parece que sim, embora um empreendimento com esse perfil implique ó estabelecimento de certas estratégias de ação; e é baseado nessa perspectiva que se formula a presente proposta.

O território do Estado da Bahia apresenta, do ponto de vista arqueológico, vasto e rico patrimônio correspondente a diferentes momentos da ocupação humana. Os sítios arqueológicos, ou seja, os lugares onde se encontram vestígios materiais que testemunham a presença de sociedade pretéritas, estendem-se por diferentes regiões, apresentando características particulares; definidas pelo período, dispositivos adaptativos (tecnológica e socialmente determinados), pelas contingências próprias da história da sociedade e pelos objetivos que cada grupo social estabeleceu para si próprio. Em função disso, os sítios arqueológicos variam 
na natureza compositiva (o tipo e a quantidade de material testemunho) e na localização (os lugares que os grupos escolheram para se instalar), podendo ser classificados como sítios de ocupação pré-coloniais, do período do contato, coloniais e pós-coloniais, abarcando os diferentes momentos históricos atravessados pelos grupos humanos que habitaram o território baiano.

No entanto, a riqueza do patrimônio arqueológico da Bahia não tem sido suficientemente explorada. Pensando nos numerosos sítios arqueológicos correspondentes às populações autóctones, por exemplo, pode-se imaginar o território como um grande arquivo documental praticamente desconhecido. De norte a sub do litoral ao cerrado, no vale sanfranciscano, que corta a caatinga, e na região central de montanhas, existem provas da existência de grupos que ocuparam, em diferentes momentos, esses espaços e ali desenvolveram formas específicas de organização social e de utilização dos recursos do ambiente.

Dentre os sítios pré-coloniais destacam-se aqueles localizados em grutas e abrigos, com representações gráficas denominadas convencionalmente de "arte" rupestre. No geral, esses sítios apresentam bom estado de conservação devido à proteção natural que atenua a ação dos agentes intempéricos. Essas pinturas e gravuras formam parte do conjunto de representações mentais de um grupo manifestações da maneira específica de perceber e aprender a natureza.

Do ponto de vista do observador contemporâneo, essas representações gráficas significam elaborações de uma linguagem estética muito distante e enigmática, posto que se desconhece o sentido e as circunstâncias em que os grafismos foram executados, por isso, apresentam-se poderosamente atrativas.

$\mathrm{Na}$ Bahia, a região de maior concentração de sítios com arte rupestre é sem dúvida a Chapada Diamantina, região central do Estado. Nessa região encontramse grutas, e abrigos, formados especialmente por calcáreos, que ofereciam condições propícias para a instalação humana.

Pesquisas sistemáticas, registros arqueológicos e notícias de informantes provam a ocorrência de sítios com artes rupestres em toda a extensão dessa formação montanhosa, englobando no perímetro de ocorrência os municípios de Lençóis, Iraquara, Wagner, Andaraí, Seabra, Morro do Chapéu, Ituaçu, Itacira dentre muitos outros.

$\mathrm{Na}$ Bahia, o conhecimento sobre os povos que desenvolveram essas tradicões pictóricas é escasso, comparando-se ao de outros Estados. Nas décadas de 60 e 70, o professor Valentín Calderón, da Universidade Federal da Bahia, realizando viagens de prospecção em diferentes lugares da Chapada Diamantina, tentou uma primeira classificação dessas pinturas rupestres, agrupando, segundo os motivos identificados, os grafismos em "tradições" estilísticas. Assim classifica a Tradição Naturalista e Simbolista, que mais tarde foram enquadradas nas denominadas Tradição Nordeste e São Francisco, respectivamente (Calderón, 1983; Guidon, 1992; Prous, 1992). No primeiro caso, as representações são monocromas (especialmente em vermelho), com predomínio de antropomorfos e zoomorfos. As figuras compõem cenas de dança, guerra, sexo, rituais e caça, que, em geral, parecem se uma seqüência discursiva, à maneira de relato de fatos. A Tradição São Francisco, por sua vez, está representada por motivos predominantemente abstratos e com marcada geometrização. No geral são composições policromas (preto, vermelho, amarelo e branco), compostas de diferentes planos superpostos, com divisões e subdivisões elaboradas. A equipe de pesquisadores da professora Beltrão, do Museu Nacional do Rio de Janeiro, que trabalha no município de Central (BA) há mais de uma década, constatou a presença de uma tradição denominada Planalto, em que sobressaem grandes motivos zoomorfos e uma inédita Tradição Astronômica, com abundância de figuras, que pareceriam aludir a sóis, estrelas e cometas (Beltrão et al., 1991).

Assim, a Chapada Diamantina apresenta vasto campo de sítios com arte rupestre que precisaria ser pesquisado profundamente e preservado.

Todo esse potencial arqueológico da região poderia ser muito bemexplorado dentro de um programa de incentivo ao turismo, a exemplo daqueles anteriormente citados. Conciliar área de interesse arqueológico com itinerários turísticos organizados poderia redundar em benefício para a população local, na preservação do patrimônio arqueológico e na divulgação dos estudos realizados. Com esse objetivo, pode-se pensar na criação de Parques Arqueológicos, nos quais ficariam reunidas diversas localidades arqueológicas, previamente estudadas, providas de infra-estrutura necessária para a visitação, devendo preencher os seguintes requisitos:

- todos os sítios contarão com tratamento especial de proteção contra o vandalismo, além de dispositivos que ao mesmo tempo facilitem e controlem a circulação dos visitantes por entre os vestígios arqueológicos;

- manutenção da cobertura vegetal nativa em área circundante aos sítios, como forma de proteger as condições ambientais que permitiram a conservação das pinturas;

- facilitação do acesso ao visitante, mediante a abertura ou melhoramento de caminhos e estradas, devidamente sinalizados, possibilitando a ligação entre os diferentes sítios;

- organização de rede de hospedagem e implantação de postos de informações, visitas, policiamento e primeiros socorros, voltados tanto para os visitantes convencionais como para os especializados (arqueólogos, etnólogos, historiadores, antropólogos, entre outros);

- instalação de um Museu do Parque Arqueológico, destinado a preservar as peças coletadas nos sítios pesquisados e a ilustrar, didaticamente, os conhecimentos alcançados pelas pesquisas;

- preparação do Centro de Convenções para reunião de especialistas ou recepção de grupos de visitas diversos (estudantis, terceira idade, entidades de classe, etc.); 
- elaboração de promoção de obras de divulgação: edições de catálogos, revistas e livros ilustrados, filmes e pôsteres, para o público com diferentes níveis de interesse.

\section{Consideraçōes Finais}

Com esses requisitos preenchidos, assegura-se a continuidade da pesquisa, possibilitando aproveitamento mais democrático dos seus resultados, posto que viabiliza a todas as pessoas interessadas o acesso direto aos conhecimentos arqueológicos. Dessa maneira, a criação de um Parque Arqueológico, com 0 conseqüente dispositivo legal para sua regulamentação, pode reverter a tendência desestruturada e, às vezes, devastadora dos empreendimentos turísticos. Ao contrário, poder-se-ia pensar que o turismo, ao mesmo tempo que incentiva a dinâmica econômica local, pode ser um elemento propiciador da proteção do patrimônio arqueológico, constituindo-se em veículo para a socialização de um conhecimento que, em geral, fica restrito a um pequeno grupo de especialistas.

\section{Referências Bibliográficas}

ANAIS DA CONFERÊNCIA Internacional sobre povoamento de América. 1996. Revista da Fundação do Museu do Homem A mericano, São Raimundo Nonato, v. 1, n. 1.

BELTRẢO, M. et al. 1991. Projeto Central: primeiros resultados. Anais do $1^{\circ}$ Simpósio de Pré-História do Nordeste Brasileiro. Recife: Universidade Federal de Pemambuco, Clío, Série Arqueológica n. 4.

BURMAN, G. 1995. As novas tendências do turismo. Bahia, Análise e Dados, Salvador, SEI/SEPLANTEC, v. 5, n. 3, p. 119-124.

CALDERON, V. 1983. Investigação sobre arte rupestre no Planalto da Bahia: as pinturas da Chapada Diamantina. Estudos de Arqueologia e Etnologia. Salvador: Universidade Federal da Bahia. p. 23-35.

DELLUC, B. et al. 1990. La Prehistoire en Perigord. Bordeaux: Editions Sud-Ouest.

GUIDON, N. 1984. L'aire archéologique du sud-est du Piaui (Brésil). Paris: Masson. 1992. As ocupações pré-históricas do Brasil (excetuando Amazônia). História dos Índios no Brasil. São Paulo: FAPESP/SMC/Companhia das Letras. p. 37-52.

LABORATOIRE DE PREHISTOIRE du Musée de L'Homme et Musée des Antiquites Nationales de Saint Gernan en Laye. 1984. Art et civilisations des Chasseurs de la Préhistoire. Paris.

LEROI-GOURHAN, A. 1992. L'art parietal Language de la Prehistoire. Grenoble: J. Millon.

PROUS, A. 1992. Arqueologia brasileira. Brasília: Universidade de Brasilia.

QUEIROZ, L. 1995. O turismo baiano no real e na competitividade intemacional. Bahia Análise e Dados, Salvador: SEI SEPLANTEC, v. 5, n. 3, p. 105-113.

VIALOU, D. 1989. Aux sources de l'art. La Prehistoire. Paris: Larousse. p. 88-112. 